\title{
Expectativas Desagregadas, Credibilidade do Banco Central e Cadeias de Markov*
}

\author{
Diogo Guillén ${ }^{\dagger}$, Márcio Garcia ${ }^{\ddagger}$
}

Contents: 1. Introdução; 2. Resenha da Literatura; 3. Metodologia; 4. Descrição dos Dados; 5. Resultados; 6 . Índice de Credibilidade ; 7. Conclusão; A. Apêndice.

Palavras-chave: Credibilidade, Banco Central, Cadeias de Markov.

Códigos JEL: $\quad$ E5, E58, E61.

Propomos e implementamos uma medida da credibilidade do Banco Central do Brasil, fazendo uso de uma base de dados com expectativas desagregadas. A hipótese é de que a heterogeneidade das expectativas de longo prazo advenha de crenças distintas com relação à aversão do Banco Central à inflação. Desse modo, a existência de agentes persistentemente otimistas ou pessimistas indicaria falta de credibilidade. Com base neste argumento, construímos um índice utilizando Cadeias de Markov. Nosso índice inova em relação aos disponíveis na literatura por considerar a dispersão das expectativas. Nossos resultados são comparados com os de outros artigos, corroborando o aprimoramento advindo da nova medida da credibilidade.

We propose and implement a measure of central bank's credibility using individual financial market agents' expectations. Our hypothesis is that long-term expectations' heterogeneity comes from different beliefs about central bank's aversion to inflation. Accordingly, the existence of persistently optimistic or pessimistic agents would reflect a credibility loss. We construct a credibility index for Brazil using Markov Chains. The novelty of our index is to consider the dispersion of inflation expectations. We compare our results with the literature, and conclude that our new measure of central bank credibility provides an improvement vis-à-vis the existing ones.

\footnotetext{
*Agradecemos à equipe da RBE, aos pareceristas, e, sobretudo, ao editor associado Alexandre Cunha, pelo excelente trabalho e paciência conosco. Agradecemos, também, aos PIBICs Beatriz Ribeiro e Felipe Lima, por eficiente assistência de pesquisa.

${ }^{\dagger}$ Princeton University. E-mail: dguillen@princeton.edu

${ }_{\ddagger}^{\ddagger}$ Professor Associado, Cátedra Vinci, Departamento de Economia, PUC-Rio. E-mail: mgarcia@econ.puc-rio.br
} 


\section{INTRODUÇÃO}

No regime de metas de inflação, a credibilidade do Banco Central é fundamental. Uma vez que é objetivo da autoridade monetária que a inflação fique dentro de uma banda determinada e, consequentemente, que as expectativas reflitam que isto ocorrerá, a credibilidade do Banco Central é condição sine qua non para que o regime de metas de inflação seja bem-sucedido.

Desse modo, é natural que a literatura tenha se proposto a avaliar a credibilidade de bancos centrais sob diferentes perspectivas: através dos erros de previsão de uma curva de Phillips (Blanchard, 1984), através da velocidade de desinflação da economia (Sargent, 1982), ou mesmo utilizando um Filtro de Kalman em uma Curva de Phillips em que o trade-off inflação/produto se altera devido à credibilidade (Hardouvelis e Barnhart, 1989).

Inicialmente, é importante especificar o que acreditamos ser credibilidade. Uma possibilidade, dita absoluta ou incondicional, é que o Banco Central entregue uma dada meta de inflação sob quaisquer circunstâncias; outra, dita relativa ou condicional, é entregar um resultado suficientemente bom levando em conta os choques que a economia sofreu. Se a definição é absoluta, então as medidas tradicionais ora utilizadas na literatura captam muito bem o que se propõe. Por outro lado, se a definição é relativa, então as medidas tradicionais podem não ser adequadas.

Neste artigo, propomos um novo método para estimar a credibilidade de um banco central utilizando expectativas desagregadas entre os agentes da economia brasileira. Se um banco central gozasse de total credibilidade, não haveria razão para que um agente fosse persistentemente pessimista ou otimista com relação à atitude de um banco central frente às pressões inflacionárias. Desse modo, sob credibilidade total, a probabilidade de um agente ser otimista ou pessimista, dado que foi pessimista no mês anterior, é a mesma.

No entanto, se falta a um banco central credibilidade e os agentes são heterogêneos com relação às suas crenças quanto à credibilidade de um banco central; isto se refletiria em uma maior persistência de agentes sendo otimistas ou pessimistas. Note que a fonte de heterogeneidade entre os agentes, por hipótese, seria o desconhecimento da verdadeira aversão à inflação de um banco central. ${ }^{1}$

Com base nestes conceitos e explorando esta base de dados, construímos um índice de credibilidade variante no tempo que parece se adequar bem ao que se supunha ser a credibilidade de um banco central em cada instante do tempo.

Além desta seção introdutória, o artigo contém mais seis seções. A próxima seção apresenta a resenha da literatura; a seção três apresenta a metodologia e sua aplicação; a quarta seção descreve os dados; a seção cinco apresenta os resultados; a sexta seção discute um índice de credibilidade e a sétima seção conclui o artigo.

\section{RESENHA DA LITERATURA}

O estudo de credibilidade de um banco central tem sido de interesse há muito tempo na literatura de macroeconomia. Desde o trabalho seminal de Kydland e Prescott (1977), em que se mostrou que um banco central discricionário gera um viés inflacionário e, consequentemente, uma solução com comprometimento seria superior, a literatura tem tentado avaliar empiricamente a credibilidade de bancos centrais. Blanchard (1984), por exemplo, já sugeria medidas para avaliar a credibilidade de um banco central. Este interesse mostrou-se ainda maior diante dos episódios de hiperinflação, em que alguns países conseguiram desinflacionar rapidamente, ao passo que outros não. ${ }^{2}$

\footnotetext{
${ }^{1}$ Uma vez que não há, teoricamente, viés sistemático nas expectativas, não haveria razão para que um agente obtivesse informação privada que o colocasse sempre como otimista ou pessimista.

${ }^{2}$ Ver Sargent (1982).
} 
Com a emergência do regime de metas de inflação, em que o objetivo é manter a inflação futura controlada, o interesse por questões referentes à credibilidade é imediato. Diante deste fato, cabe comentar alguns artigos da literatura.

Razzak (2001) estuda o papel de credibilidade a partir do prisma do trade-off de política monetária. A hipótese é que um banco central crível, que mantém a inflação e a respectiva variância baixas por um longo período de tempo, reduz a correlação entre o crescimento da oferta de moeda e a inflação. Dessa maneira, tudo mais constante, uma expansão monetária aumentaria o produto real relativamente mais do que aumentaria a inflação, o que sugere um ganho devido à maior credibilidade. Os resultados sugerem que os bancos centrais da Austrália, Nova Zelândia e Suécia são críveis, ao passo que, para Canadá e Reino Unido, os resultados não são tão contundentes.

Um estudo de credibilidade bastante distinto dos demais foi proposto por Blinder (1999). No artigo, Blinder constrói uma pesquisa com perguntas sobre credibilidade de um banco central que foram respondidas por banqueiros centrais e acadêmicos. Os resultados mostram que os banqueiros centrais consideram credibilidade muito importante, principalmente por tornar períodos desinflacionários menos custosos, por ser mais fácil manter a inflação baixa, por tornar mais fácil defender a moeda e por permitir angariar apoio para a independência do banco central. Segundo os participantes da amostra, a credibilidade pode ser obtida, basicamente, ao manter uma história coerente de combate à inflação.

Svensson (1993) propõe o que ele considera ser o teste mais simples para avaliar credibilidade de um regime de metas de inflação. Segundo este autor, há dois conceitos de credibilidade: credibilidade absoluta, quando os agentes acreditam que a probabilidade da inflação futura ficar dentro da banda proposta no regime de metas de inflação é de $100 \%$, e credibilidade nas expectativas, quando o valor esperado da taxa de inflação futura está contido na banda proposta pelo banco central. Tomando como base tais conceitos, o artigo propõe identificar quais seriam as taxas máximas e mínimas consistentes com o regime de metas de inflação. Considera-se a taxa de um título nominal para então subtrair desta taxa a inflação consistente com o regime de metas. Assim, temos, a partir de um título nominal, a taxa real consistente com o regime de metas de inflação. O teste proposto é avaliar se a taxa real consistente é maior ou menor do que a taxa real observada. Se a taxa real estiver fora da banda entre o mínimo e o máximo consistente, pode-se rejeitar credibilidade absoluta e credibilidade em expectativas. ${ }^{3}$ Os resultados sugerem que não havia credibilidade no início do regime de metas de inflação no Canadá e na Nova Zelândia e, além disso, a Suécia não tinha credibilidade.

Hardouvelis e Barnhart (1989) sugerem a utilização de um modelo com Filtro de Kalman para avaliar a resposta dos preços de commodities aos anúncios semanais do M1. Os resultados mostram que há mudança na resposta dos preços de commodities, o que é visto como alteração da credibilidade do banco central.

Cecchetti e Krause (2002), em um artigo que avalia a eficiência, transparência e credibilidade de bancos centrais de 24 países, sugerem um índice que toma valor um (1) se a expectativa de inflação for igual ou inferior à meta e assume valor zero (0) se a expectativa de inflação for igual ou superior a $20 \%$. No intervalo entre os dois extremos, o índice cai linearmente.

Deve ser ressaltado, ainda, que a literatura de mensuração da credibilidade do Banco Central brasileiro também é rica.

Garcia e Lowenkron (2007) propõem um teste semelhante ao de Svensson (1993), para avaliar se as surpresas inflacionárias de curto prazo afetam as expectativas de longo prazo. Os resultados para o caso brasileiro sugerem que o Banco Central tem carência de credibilidade, mas que houve ganho de credibilidade no final da amostra (2006).

Sicsú (2002) propõe um índice de credibilidade baseado na distância entre a inflação esperada e o centro da meta de inflação, semelhante a Cecchetti e Krause (2002). Com base nisto, mostra que o

\footnotetext{
${ }^{3} \mathrm{O}$ autor também sugere a utilização de surveys para avaliar se as expectativas são consistentes com o regime de metas de inflação.
} 
Banco Central consegue alterar as expectativas caso tenha tido sucesso recente na condução da política monetária. Além disso, o autor ressalta que, utilizando o coeficiente de Pearson como medida de heterogeneidade, as expectativas são heterogêneas quando o $\mathrm{BCB}$ consegue acumular reputação e as metas de inflação estão em processo de perda de credibilidade, como em 2001.

Nahon e Meurer (2005), assim como Mendonça e Souza (2007), investigam qual seria o melhor índice para medir a credibilidade do Banco Central utilizando variações do índice de Sicsú (2002) e Cecchetti e Krause (2002). Os resultados encontrados são muito semelhantes aos de Cecchetti e Krause (2002), como mostraremos posteriormente no artigo.

\section{METODOLOGIA}

Nesta seção, apresentamos, inicialmente, a ideia de utilizar Cadeias de Markov para o estudo de credibilidade, pois esta será a base da metodologia aqui empregada. Posteriormente, damos um exemplo hipotético para melhor entendimento da metodologia. No apêndice, apresentamos uma breve explicação de Cadeias de Markov e uma simulação teórica que embasa nossa ideia de credibilidade.

\subsection{A aplicação para o estudo de credibilidade}

Neste artigo, utilizamos o arcabouço de Cadeias de Markov e matrizes de transição para avaliar a credibilidade de um banco central. Utilizando uma base de dados restrita ao Banco Central do Brasil, composta pelas expectativas reportadas por todos os agentes para a Pesquisa de Expectativas de Mercado (Focus), ${ }^{4}$ avaliamos como cada um dos agentes se comporta com relação às expectativas do IPCA.

Se um Banco Central possui credibilidade total, não haveria razão de ser otimista ou pessimista com relação à inflação. Dessa maneira, o que deveria ser observado é que a probabilidade de um agente ser pessimista, dado que foi pessimista no mês anterior, é a mesma de se tornar otimista. ${ }^{5}$ Assim sendo, a medida de credibilidade advém direta e naturalmente das probabilidades de transição do ranking de expectativas.

A fonte de heterogeneidade persistente é a desconfiança do combate à inflação. Naturalmente, esta hipótese é forte e deve ser mais bem explicitada.

A primeira crítica que surge é a possibilidade de informação privada advinda, por exemplo, de coleta de preços. Muitos previsores utilizam coleta para tentar replicar o índice de preços sobre os quais estão sendo feitas as expectativas. A hipótese, então, é que a coleta de preços ajuda a prever o curto prazo, mas se utilizarmos um prazo suficientemente longo, isto não impactará as expectativas.

Uma segunda crítica, um pouco mais tênue, refere-se ao custo que o previsor tem de alterar sua expectativa. Se um agente divulga a seus clientes, por exemplo, que acredita que a inflação será de $5 \%$, ele não pode alterar sua expectativa na semana seguinte para $5,1 \%$. O previsor só alterará sua expectativa quando a mudança for significativa e os ganhos de alterar forem maiores do que o custo. 0 argumento para inércia das expectativas é concreto, mas não há razões para que afete qualitativamente os resultados, pois este argumento não altera as mudanças temporais nas probabilidades de transição. Desse modo, a mudança de credibilidade não seria afetada pela credibilidade do previsor, no que diz respeito à validação de sua opinião original. Neste mesmo campo, existe a crítica quanto à possibilidade de comportamento estratégico dos agentes, isto é, um agente que opta racionalmente por não colocar a sua verdadeira expectativa. Tal comportamento é bastante improvável por alguns motivos. Em primeiro lugar, o Banco Central possui um ranking das instituições que melhor prevêem a inflação e isto é divulgado para o mercado. Desse modo, os incentivos parecem se alinhar. Além disso, como há

${ }^{4}$ Pesquisa do Banco Central de coleta de expectativas junto a agentes do mercado financeiro.

${ }^{5}$ As definições de otimista, pessimista e mediano serão dadas na próxima seção. 
muitos agentes fornecendo expectativas, a mudança da expectativa marginal de um agente não tem efeito quase nenhum sobre as estatísticas agregadas, tais como a média ou, sobretudo, a mediana, que são apresentadas semana a semana.

Por fim, a última crítica refere-se à hipótese de que os agentes conhecem todo o modelo, exceto a aversão do banco central à inflação. Esta hipótese é forte, mas deve ser lembrado que, no Brasil, dado o caráter recente do histórico de combate à inflação, é natural que a aversão à inflação seja o parâmetro sobre o qual incide mais incerteza.

No entanto, tal como foi exposto anteriormente, as probabilidades de transição não costumam ser variantes no tempo, ao passo que a credibilidade, tal como proposto por Hardouvelis e Barnhart (1989), é variante no tempo. Dessa forma, para permitir que a credibilidade se altere, identificamos as probabilidades de transição referentes apenas à mudança de um mês para outro, de tal forma que temos o que poderia ser chamado de "rolling transition matrix".

Já tendo sido explicado o tema da credibilidade variante no tempo, o segundo passo é identificar os estados que compõem as cadeias de Markov. Com as expectativas desagregadas por agente em cada instante do tempo, é possível montar uma ordenação de expectativas, identificando em que percentil cada agente estaria, do mais otimista (expectativas baixas) até o mais pessimista (expectativas altas). Dessa maneira, temos três estados: otimista, mediano e pessimista, baseados na colocação da expectativa do agente no ranking de expectativas do mês em questão. ${ }^{6}$

Um agente $i$, no período $t$, com uma expectativa para $t+h$ é:

Table 1: Ranking de expectativas a cada instante

$$
\left\{\begin{array}{l}
\text { Pessimista }-33,3 \% \text { expectativas mais altas } \\
\text { Mediano }-33,3 \% \text { expectativas medianas } \\
\text { Otimista }-33,3 \% \text { expectativas mais baixas }
\end{array}\right.
$$

Um último ponto a considerar refere-se ao horizonte de expectativa que tomaremos. Daremos maiores detalhes, em virtude da disponibilidade de dados, na próxima seção.

Antes de apresentarmos os resultados, daremos um exemplo hipotético para que se possa entender melhor a metodologia empregada.

\subsection{Exemplo hipotético}

Suponha uma economia formada por $n$ agentes em três períodos de tempo. Para facilitar, observamos uma amostra com cinco agentes para avaliar como estes se comportam. Tendo construído um ranking para as expectativas, encontramos a seguinte matriz de estados em cada período do tempo para os cinco agentes selecionados.

Isto significa que, por exemplo, o agente 1 era pessimista no primeiro instante, tornou-se mediano no segundo instante e voltou a ser pessimista no terceiro instante. Dessa maneira, tal como definimos pessimista, nos instantes 1 e três, suas expectativas estavam entre as 33\% mais altas.

Tendo construído esta matriz, avaliamos a matriz de probabilidades de transição da economia hipotética apresentada.

Veja que, por exemplo, a probabilidade de um agente pessimista tornar-se mediano é de $60 \%$, resultado imediato, uma vez que há cinco ocorrências de agente pessimista nos dois primeiros instantes,

\footnotetext{
${ }^{6}$ Duas razões nos levaram a utilizar três estados: em primeiro lugar, a possibilidade de uma interpretação intuitiva, utilizando os conceitos de otimistas, pessimistas e medianos. Em segundo lugar, como temos cerca de oitenta agentes em cada instante, a construção de mais estados seria comprometida por um número de agentes reduzido em cada um dos estados.
} 
Table 2: Exemplo

\begin{tabular}{cccc}
\hline Agente/instante & $t=1$ & $t=2$ & $t=3$ \\
\hline 1 & 1 & 2 & 1 \\
2 & 2 & 1 & 2 \\
3 & 1 & 1 & 3 \\
4 & 3 & 1 & 2 \\
5 & 2 & 2 & 1 \\
\hline
\end{tabular}

1: Pessimista

2: Mediano

3: Otimista

Table 3: Probabilidades de transição

\begin{tabular}{cccc}
\hline & 1 & 2 & 3 \\
\hline 1 & 20,00 & 60,00 & 20,00 \\
2 & 75,00 & 25,00 & 0,00 \\
3 & 100,00 & 0,00 & 0,00 \\
\hline
\end{tabular}

sendo que três deles tornam-se medianos no período seguinte; logo a probabilidade é de $60 \%$. De maneira análoga, há quatro ocorrências de agente mediano, sendo que apenas um deles se mantém mediano: $25 \%$.

No entanto, note que estamos considerando tanto as ocorrências do instante $t=1$ para o instante $t=2$, quanto do instante $t=2$ para $o$ instante $t=3 \mathrm{Tal}$ como motivamos anteriormente, a crença da literatura é de que esta probabilidade se altera ao longo do tempo. Diante deste fato, devemos avaliar as probabilidades de transição em cada instante de tempo. Desse modo, temos duas matrizes de transição: uma para a transição do primeiro instante para o segundo instante, e outra para a transição do segundo para o terceiro instante.

Table 4: Probabilidades no primeiro período

\begin{tabular}{cccc}
\hline \multicolumn{4}{l}{$t=1 \rightarrow t=2$} \\
\hline 1 & 50,00 & 50,00 & 0,00 \\
2 & 50,00 & 50,00 & 0,00 \\
3 & 100,00 & 0,00 & 0,00 \\
\hline
\end{tabular}

A utilização de matrizes de transição para cada par de instantes permite que a credibilidade seja variante no tempo. Se, na primeira matriz, a probabilidade de um agente permanecer pessimista era de $50 \%$, na segunda matriz esta probabilidade é de $0 \%$. Estas mudanças são muito grandes em virtude 
Table 5: Probabilidades no segundo período

\begin{tabular}{cccc}
\hline \multicolumn{4}{l}{$t=2 \rightarrow t=3$} \\
\hline 1 & 0,00 & 66,67 & 33,33 \\
2 & 100,00 & 0,00 & 0,00 \\
3 & 0,00 & 0,00 & 0,00 \\
\hline
\end{tabular}

do fato de estarmos dando um exemplo hipotético com apenas cinco agentes, ao passo que a base de dados utilizada é mais extensa.

Por fim, cabe ressaltar que uma alta probabilidade de se manter otimista não é evidência de grande credibilidade. Tal como explicamos anteriormente, se houvesse credibilidade perfeita, as probabilidades de se manter em cada um dos estados seriam as mesmas; a matriz teórica sob credibilidade total é apresentada na Tabela 6:

Table 6: Matriz de transição teórica sob credibilidade total

\begin{tabular}{cccc}
\hline & 1 & 2 & 3 \\
\hline 1 & 33,33 & 33,33 & 33,33 \\
2 & 33,33 & 33,33 & 33,33 \\
3 & 33,33 & 33,33 & 33,33 \\
\hline
\end{tabular}

Dessa maneira, a falta de credibilidade pode ser identificada a partir das variações com relação à probabilidade teórica. Quanto maiores forem as diferenças absolutas entre a probabilidade teórica e a probabilidade observada, menor será a credibilidade do banco central. Assim sendo, daremos grande importância às probabilidades de se permanecer no mesmo estado, pois isto reflete bem nossa ideia de falta ou não de credibilidade.

Uma objeção que surge a este índice é que ignoramos o nível em si das expectativas. É possível que todos os agentes estivessem aleatoriamente distribuídos, mas que fosse em um nível bastante superior à meta. Em primeiro lugar, os índices de credibilidade costumam ignorar choques que afetam a economia e que tornam mais dificil atingir o centro da meta. Desse modo, a crença de que os índices de credibilidade que utilizam a meta estariam de fato captando credibilidade é um pouco exagerada. Por isto, pode-se argumentar que a não utilização de qualquer variável de nível faz do índice de credibilidade a partir do ranking de expectativas complementar aos demais índices já existentes na literatura. De todo modo, apresentaremos, no corpo do artigo, uma variante deste índice que leva em consideração a meta das expectativas.

Os dados utilizados referem-se às expectativas desagregadas por agente do IPCA coletadas no survey do Banco Central.

Os agentes são chamados a responder a esta pesquisa todos os dias, mas só temos a expectativa na data de divulgação do IPCA-15, data que serve como base para a construção do ranking do Banco Central.

Desse modo, ainda que fosse melhor termos dados semanais, não é descabido dizer que as expectativas obtidas refletem, da maneira mais verossímil, as verdadeiras crenças da economia. 
A pesquisa é aberta para quaisquer agentes que queiram participar e apresentem evidência de robustez em suas expectativas. ${ }^{7}$ Note que isto nos leva a 153 agentes ao longo de toda a pesquisa. No entanto, deve ser mencionado que nem todos os agentes que participam da pesquisa de fato a respondem. Normalmente, há cerca de 80 agentes que divulgam suas expectativas na Pesquisa Focus. Mais ainda, é bastante comum encontrarmos um mesmo agente que divulgue suas expectativas para um horizonte, mas não divulgue para outro. Dando um exemplo mais concreto, é bastante comum encontrarmos agentes que divulguem suas expectativas para o mês subsequente, mas que não divulguem para onze ou doze meses à frente. Isto é extremamente importante, pois nosso interesse é por expectativas com maiores prazos, que sofrem mais da ausência de respostas na pesquisa.

Para facilitar o entendimento da base de dados, apresentamos a Figura 1.

\section{DESCRIÇÃO DOS DADOS}

A pesquisa apresenta vários agentes fornecendo suas expectativas para um mês à frente, seis meses à frente, etc. Com estas expectativas, construímos um ranking de expectativas, em cada instante do tempo e para cada horizonte de expectativa, que posteriormente é utilizado para avaliarmos credibilidade com base na metodologia anteriormente apresentada.

Além disso, apresentamos os dados para expectativas mais longas, referentes ao ano-calendário $t+1, t+2, t+3, t+4$.

Table 7: Número de agentes com expectativas com horizontes longos

\begin{tabular}{ccc}
\hline & $\begin{array}{c}\text { Número médio de } \\
\text { agentes por período }\end{array}$ & $\begin{array}{c}\text { Número de agentes que divulgou } \\
\text { esta expectativa no período }\end{array}$ \\
\hline Ano $t+1$ & 62,95 & 131 \\
Ano $t+2$ & 45,76 & 101 \\
Ano $t+3$ & 42,46 & 92 \\
Ano $t+4$ & 34,62 & 90 \\
\hline
\end{tabular}

Na Tabela 7, apresentamos duas dimensões distintas que ajudam a elucidar a maneira como a base se constitui. Em primeiro lugar, apresentamos o número médio de agentes que divulgou as expectativas a cada período. Para quatro anos à frente, por exemplo, cerca de 34 agentes divulgavam suas expectativas.

Por outro lado, outra dimensão importante é saber quem são estes agentes, isto é, tentar identificar se são, por exemplo, os mesmos 34 sempre, ou se estes se alternam. Os resultados mostram que, novamente, quanto mais distante for o horizonte das expectativas, menor o número de agentes que divulgaram esta expectativa no período.

\section{RESULTADOS}

Tendo identificado as matrizes de transição para cada par de meses que compõem a amostra, podemos apresentar os resultados de credibilidade. Como forma de suavizar as mudanças nas probabilidades de transição, os gráficos apresentados são a média móvel de três meses das probabilidades.

\footnotetext{
${ }^{7}$ Marques et alii (2003).
} 


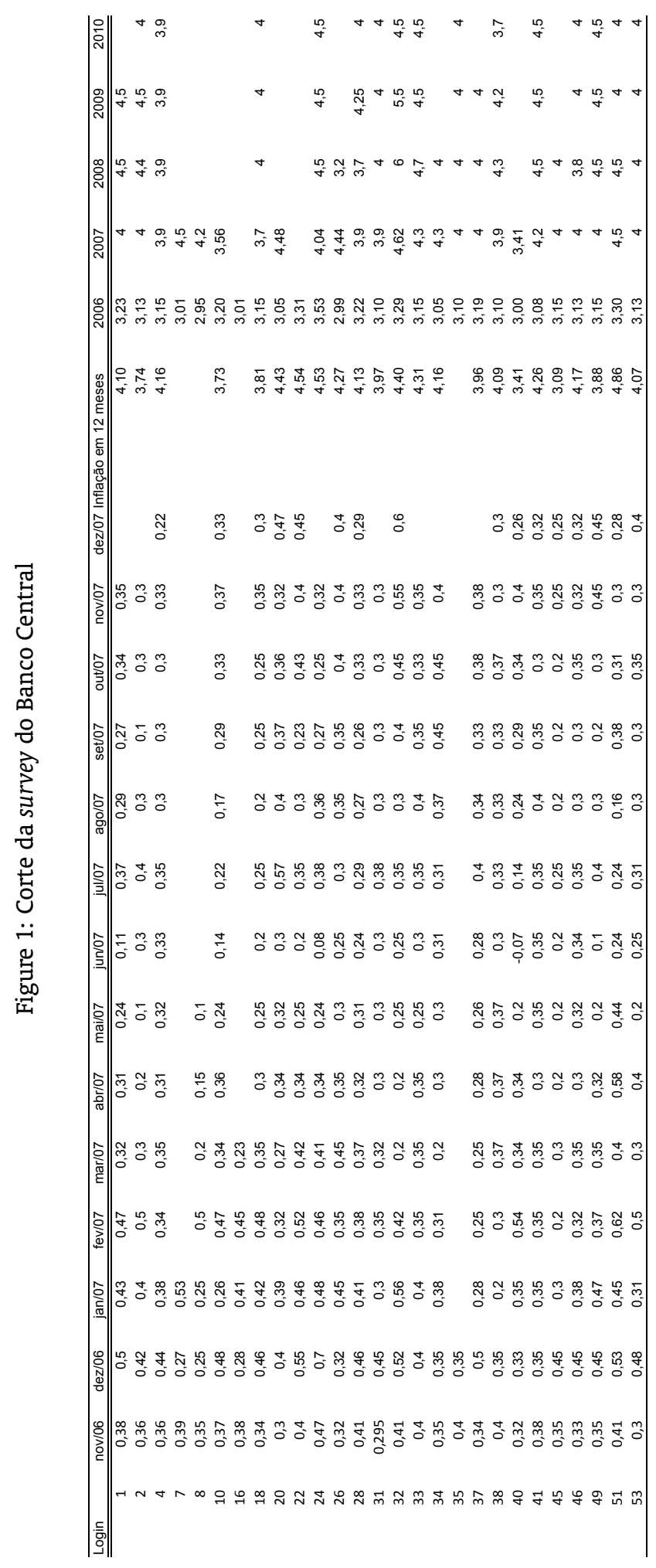


Com o intuito de organizar a exposição dos resultados, apresentaremos os resultados utilizando expectativas mensais (horizontes de um mês, seis meses e doze meses). Na seção seguinte, propomos um índice de credibilidade.

\subsection{Resultados mensais}

Os resultados apresentados referem-se aos horizontes de um mês, seis meses e doze meses acumulados. Note que, se acreditarmos que as probabilidades de transição refletem a credibilidade, não haveria razão para que encontrássemos resultados semelhantes para um mês e doze meses, uma vez que a expectativa para um mês à frente não é afetada por credibilidade. Considerando o mecanismo de transmissão de política monetária e a inércia inflacionária, a expectativa para um mês à frente não é fruto de credibilidade, mas de crenças com relação à inflação corrente para as quais o Banco Central nada mais pode fazer. Dessa maneira, só apresentaremos, en passant, os resultados para um mês como controle para avaliar a inflação corrente. A expectativa de doze meses ainda pode ser considerada um prazo curto para a avaliação do regime de metas de inflação, mas optamos por utilizar este prazo por ser o maior prazo em que há certa estabilidade nas expectativas desagregadas concomitante à variância entre os agentes. Quando observamos prazos maiores, os reajustes são esporádicos, dificultando uma análise mais precisa. De todo modo, apresentamos a análise para prazos mais longos no Apêndice.

Mais ainda, a apresentação das expectativas de um mês à frente permite distinguir a fonte de heterogeneidade das expectativas. É natural pensarmos que a fonte de heterogeneidade destas expectativas seja advinda de informação privada do agente com relação a algum reajuste de preço específico (coleta de preços). No entanto, quando analisamos horizontes mais longos, a informação privada não parece ser tão determinante. O mais importante, nestes casos, é a avaliação de cada agente sobre como o banco central se comportará para reduzir a inflação. Desse modo, a incerteza com relação à aversão à inflação do banqueiro central assume papel preponderante e, mais ainda, o que se discute, portanto, é a credibilidade do banco central.

Veja, então, que a fonte de heterogeneidade que nos interessa, e que acreditamos ser melhor captada em horizontes mais longos, é a referente à credibilidade do banco central.

Outro comentário refere-se a utilizarmos a expectativa do resultado acumulado de seis e doze meses em detrimento das expectativas pontuais para horizontes mais longos; por exemplo, a previsão para o $12^{\circ}$ mês a contar a partir de quando se faz a expectativa. Analisando a pesquisa do Banco Central, vemos que o desvio padrão médio da amostra é de aproximadamente 0.11 para todos os horizontes. ${ }^{8}$ Quando utilizamos, por exemplo, o acumulado em doze meses, o desvio padrão aumenta para cerca de 0.66 , indicando uma maior dispersão dos resultados. Uma vez que nossos resultados avaliam a posição de certo agente no ranking entre os agentes, precisamos de maior dispersão para ter certeza de que, quando efetivamente um agente deixa de ser pessimista e torna-se mediano, isto não significa que houve uma mudança mínima nas expectativas, mas que de fato o agente alterou sua análise da futura política do Banco Central. Tome, como exemplo, que os agentes acreditassem que a inflação mensal para o $12^{\circ}$ mês seria $0,5 \%$, mas que houvesse muito pouca heterogeneidade. Desse modo, um agente que acreditasse que a inflação seria $0,45 \%$ seria visto como otimista; no entanto, se passasse a achar que a inflação seria $0,55 \%$ seria tachado de pessimista. Notadamente, isto não é uma mudança de percepção de política, apenas de crença pontual.

Além disso, fazemos os testes para ano-calendário: desde o ano seguinte à data em que a expectativa foi tomada, até quatro anos após esta mesma data.

\footnotetext{
${ }^{8}$ Este desvio padrão foi calculado pelos autores, não é o reportado pelo Banco Central.
} 


\subsubsection{Probabilidade de continuar no mesmo estado}

Uma primeira análise refere-se à probabilidade de um agente continuar no mesmo estado (pessimista, otimista ou mediano) de um mês para outro. Os resultados são apresentados nas figuras 2, 3 e 4 .

Figure 2: Comportamento dos agentes otimistas (um mês, seis meses e doze meses)

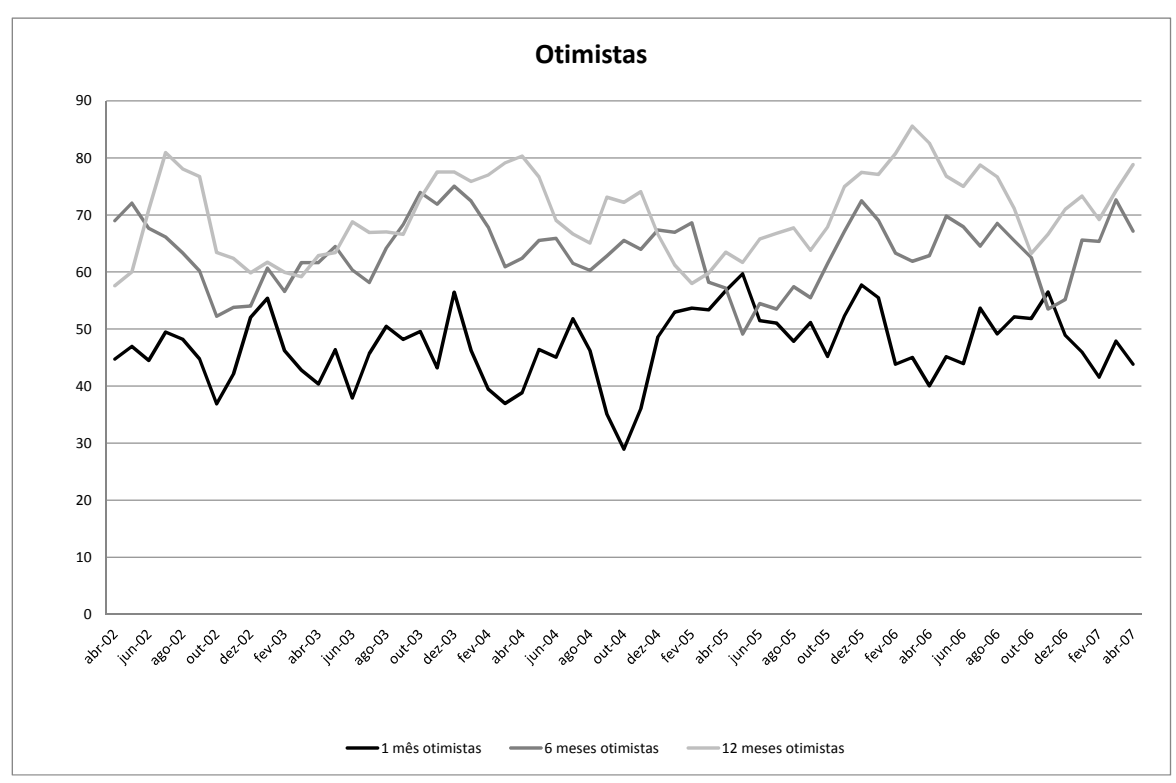

Conforme pode ser observado, o primeiro ponto que chama atenção refere-se ao fato de que o comportamento das probabilidades de transição para expectativas acumuladas para os próximos seis e doze meses é semelhante, mas bastante distinto do que é observado para as expectativas para um mês à frente. Este comportamento distinto das expectativas sugere que a fonte de heterogeneidade para horizontes mais longos é distinta da fonte para horizontes mais curtos, tal como sugerimos anteriormente.

Além disso, a probabilidade de permanecer no mesmo estado é maior para horizontes mais longos, principalmente em caso de agentes otimistas ou pessimistas. Cabe ressaltar, então, que estes dois argumentos sugerem que estamos de fato captando a credibilidade ao utilizar matrizes de transição de expectativas com horizontes mais longos. Conforme dito anteriormente, é de se imaginar que o comportamento para seis e doze meses seria distinto das probabilidades para um mês à frente. Vale mencionar que o coeficiente de correlação entre as expectativas de seis e doze meses para agentes otimistas é de 0,43 , ao passo que o coeficiente de correlação entre as séries de probabilidade das expectativas para um mês e doze meses para otimistas é de $-0,25$. Além disso, o fato de termos encontrado probabilidades maiores de se permanecer no mesmo estado, isto é, maior evidência de que não há uma distribuição aleatória dos agentes, tal como ocorreria se houvesse credibilidade, sugere que em curtos horizontes outros fatores definem a mudança do ranking das expectativas.

\subsubsection{Análise para expectativas acumuladas para seis e doze meses}

Para entender melhor os resultados anteriores, apresentamos os resultados agregados pelo horizonte da expectativa. Não apresentaremos os resultados para um mês à frente, pois o interesse 
Figure 3: Comportamento dos agentes medianos (um mês, seis meses e doze meses)

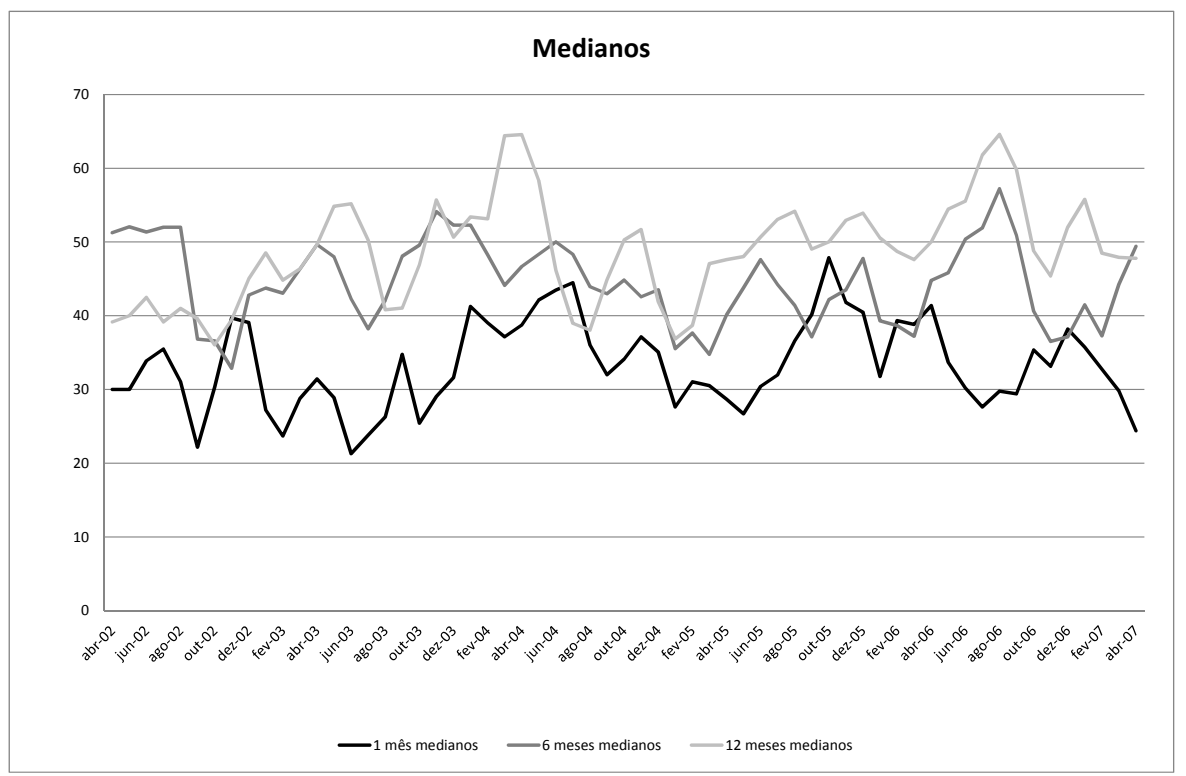

Figure 4: Comportamento dos agentes pessimistas (um mês, seis meses e doze meses)

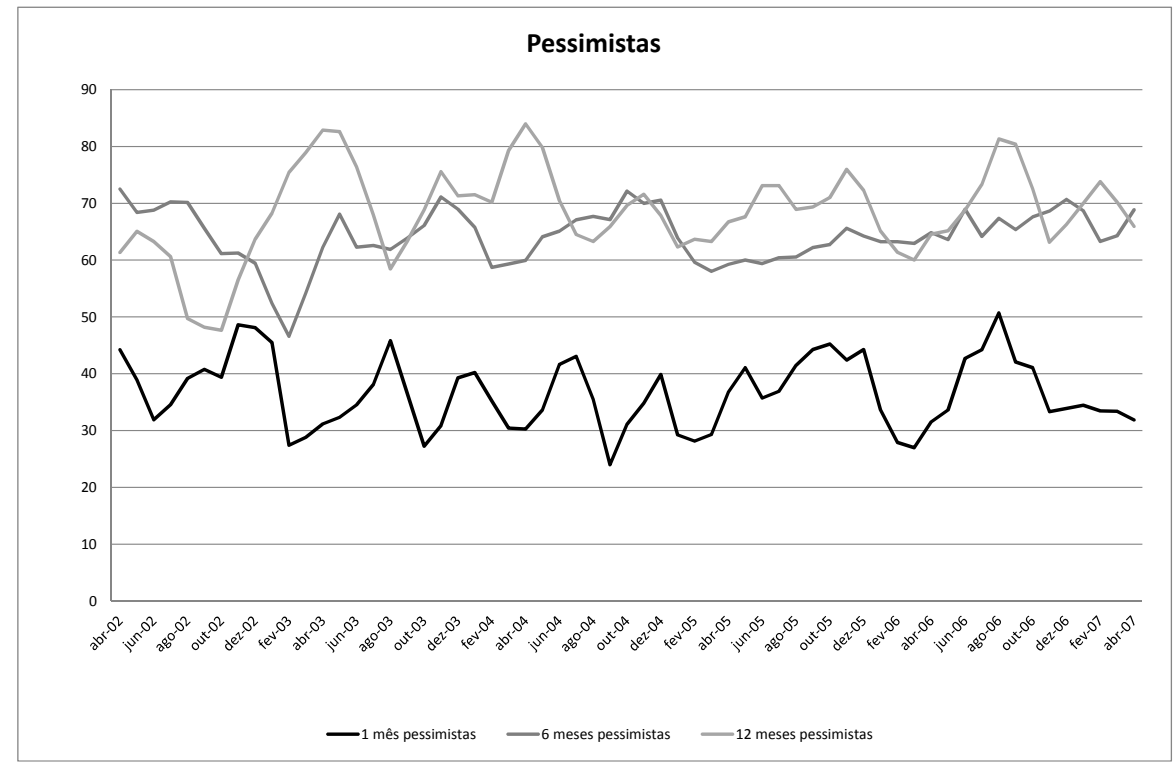


por prazos curtos de expectativas foi apenas o de mostrar que a fonte de heterogeneidade é diferente daquela que se evidencia em prazos mais longos.

Figure 5: Comportamento das expectativas para seis meses à frente (acumulado)

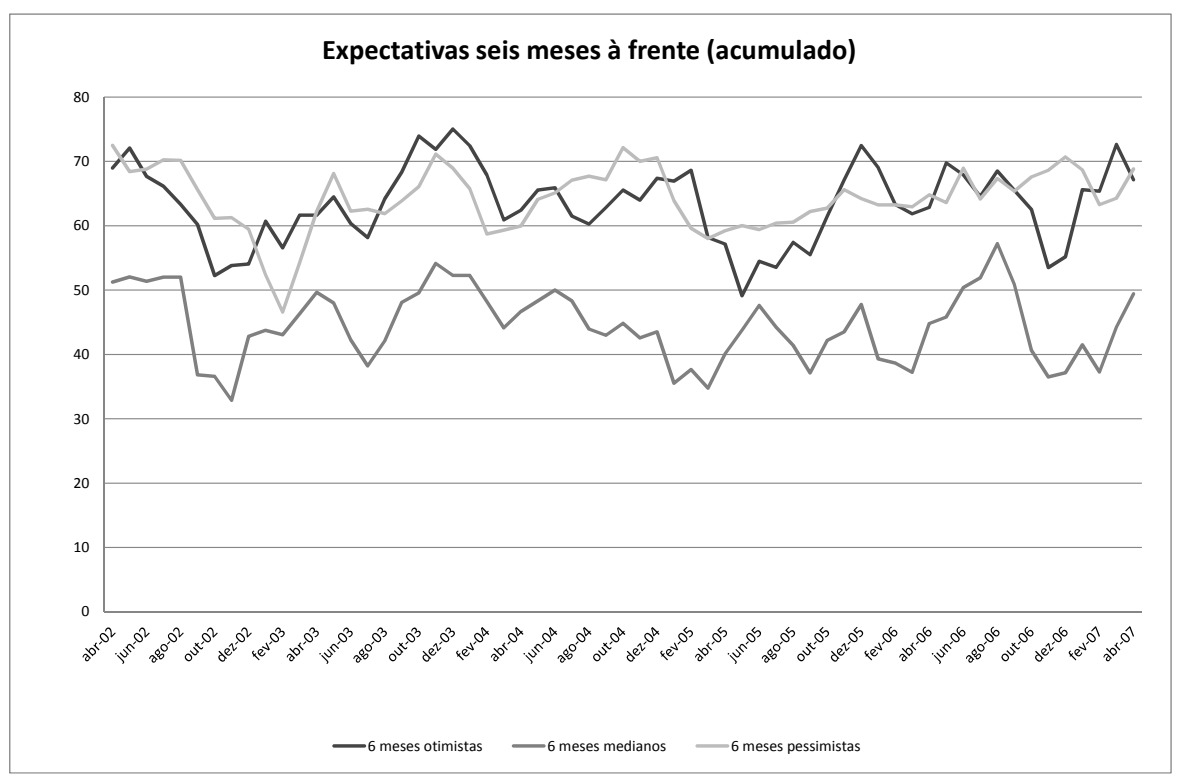

Estes gráficos complementam a análise anterior ao permitir que possamos ver como agentes otimistas, pessimistas e medianos, para um dado horizonte de expectativas, se comportam, permitindo uma comparação entre eles ao longo do tempo.

A conclusão imediata que emerge destes resultados é que o comportamento dos otimistas se assemelha bastante ao dos pessimistas, não só em suas mudanças ao longo do tempo, como também no valor absoluto da probabilidade. Veja que, por exemplo, no fim de 2004, todas as séries de seis e doze meses apresentaram uma queda na probabilidade de se manter no mesmo estado. É interessante perceber que, quando há um aumento na probabilidade de um agente pessimista continuar pessimista, o mesmo fenômeno ocorre para agentes otimistas, ${ }^{9}$ o que sugere falta de credibilidade. Agentes que são otimistas continuam sendo otimistas, ao passo que agentes pessimistas continuam sendo pessimistas, independente da política do Banco Central.

Outro ponto que deve ser comentado refere-se ao comportamento dos agentes medianos. Conforme pode ser visto, a probabilidade de um agente mediano permanecer mediano no período seguinte tende a ser menor do que a probabilidade de continuar otimista ou pessimista. No entanto, o comportamento da série de agentes medianos se assemelha bastante às demais séries. Para melhor explicitar este ponto, apresentamos a Tabela 8.

Na Tabela 8, apresentamos os coeficientes de correlação entre as probabilidades de transição de se permanecer no mesmo estado para expectativas acumuladas de seis meses (diagonal inferior) e para expectativas acumuladas de doze meses (diagonal superior). Esta tabela condensa duas matrizes de correlação: uma para expectativas de seis meses (diagonal inferior) e outra para expectativas de doze meses (diagonal superior). Veja que, por exemplo, o coeficiente de correlação entre medianos e otimistas para doze meses é 0,47 e, para seis meses, é 0,56. Conclui-se, desse modo, que os agentes comportam-se

\footnotetext{
${ }^{9}$ Exceto em 2002, meados de 2006 e no início de 2007.
} 
Figure 6: Comportamento das expectativas para doze meses à frente (acumulado)

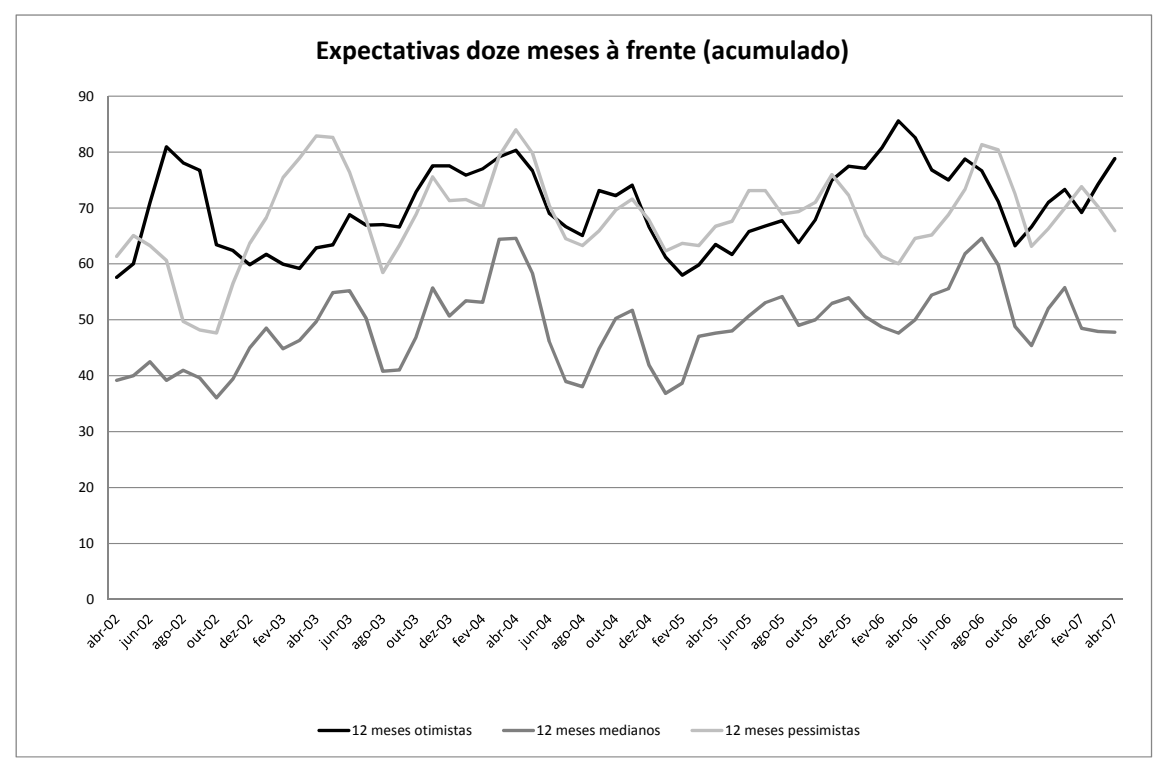

Table 8: Coeficientes de correlação

\begin{tabular}{cccc}
\hline 6 meses / 12 meses & Otimistas & Medianos & Pessimistas \\
\hline Otimistas & 1,00 & 0,47 & 0,05 \\
Medianos & 0,56 & 1,00 & 0,75 \\
Pessimistas & 0,44 & 0,33 & 1,00 \\
\hline
\end{tabular}

de maneira semelhante, sejam otimistas, medianos ou pessimistas. O importante é perceber, dessa maneira, que as crenças se mantêm no tempo, sugerindo uma medida de credibilidade variante no tempo.

\subsection{Resultados para ano-calendário}

Nesta seção, apresentamos resultados utilizando expectativas para anos-calendários subsequentes. Deste modo, expectativas de janeiro de 2002 ou de agosto de 2002 serão tratadas da mesmo modo, pois estarão avaliando a inflação em 2003.

Em primeiro lugar, cabe ressaltar que o número de agentes fornecendo expectativas para estes horizontes é menor, conforme foi visto na Tabela 7.

Uma vez tendo feito estas ressalvas, podemos mostrar os resultados para os dados anuais. Nesta seção, apresentamos os dados para o ano seguinte, mas no apêndice constam os dados para $t+2, t+3$ e $t+4$.

Da mesma forma que apresentado anteriormente, a Figura 7 mostra os resultados para o comportamento das expectativas para o ano seguinte. 
Figure 7: Comportamento das expectativas para um ano à frente

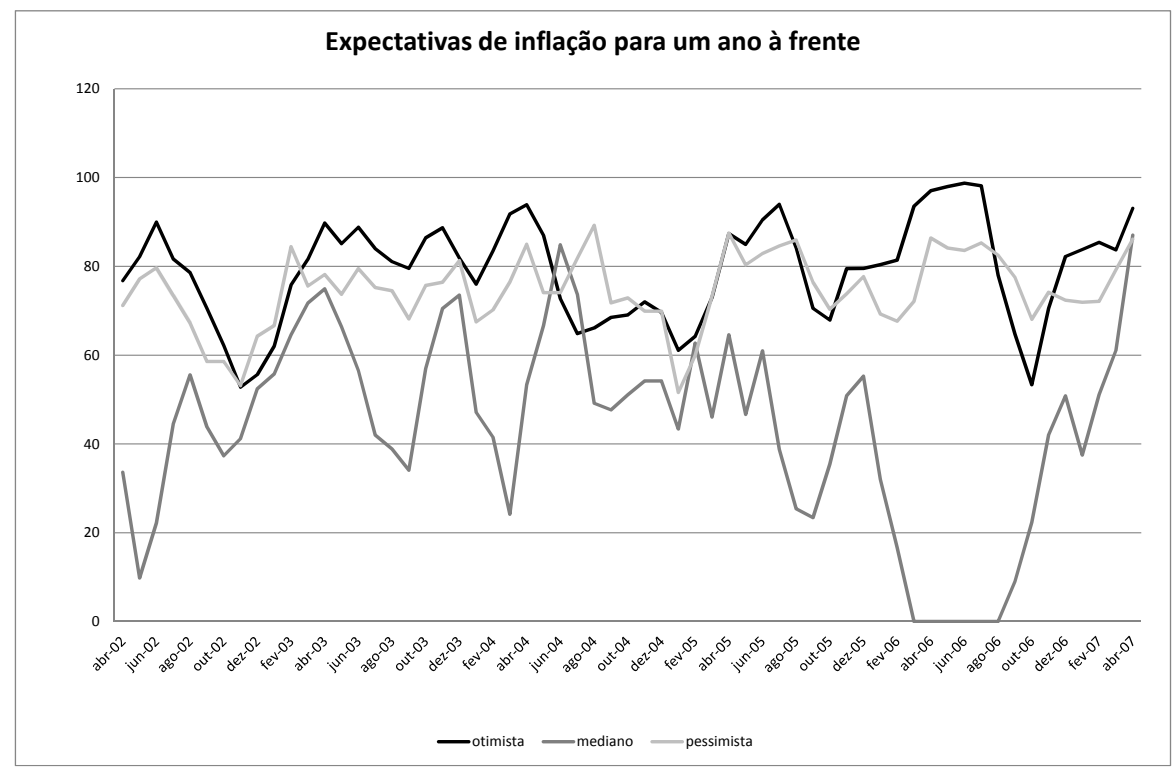

Os resultados confirmam as conclusões anteriores de que os agentes otimistas e pessimistas comportam-se de maneira semelhante. A queda para zero na série de agentes medianos ocorre porque há uma polarização das expectativas, concomitante a um número reduzido de agentes fornecendo estas expectativas, o que acaba fazendo com que não haja agentes no intervalo mediano: $33 \%$ a $66 \%$ no ranking das expectativas.

Os resultados para dois, três e quatro anos à frente são apresentados no apêndice. De forma geral, os resultados parecem ser muito voláteis devido ao número reduzido de agentes. De todo modo, note-se que as probabilidades de se manter no mesmo estado são maiores, quanto maior for o horizonte sobre o qual são feitas as expectativas.

\section{6. ÍNDICE DE CREDIBILIDADE}

Os resultados anteriormente apresentados permitem entender o comportamento dos agentes diante do Banco Central. No entanto, não construímos uma medida única de credibilidade até agora. Nesta seção, propomos um índice de credibilidade variante no tempo, inédito na literatura. Apresentamos, inicialmente, os índices de credibilidade já existentes na literatura e, então, apresentamos o índice proposto neste artigo.

\section{1. Índices de Credibilidade na literatura}

Conforme citamos na resenha da literatura, há vários índices que tentam mensurar a credibilidade de um banco central. Nesta seção, apresentamos alguns deles, semelhantes entre si, que se baseiam em Cecchetti e Krause (2002). 
Cecchetti e Krause (2002) constroem um índice de credibilidade da seguinte forma:

$$
I C^{C K}=\left\{\begin{array}{c}
1, \text { se } E(\pi) \leq \pi^{t} \\
1-\frac{1}{0.2-\pi^{t}}\left[E(\pi)-\pi^{t}\right], \text { se } \pi^{t}<E(\pi)<20 \% \\
0, \text { se } E(\pi) \geq 20 \%
\end{array}\right.
$$

Este índice sugere que há credibilidade total se a expectativa de inflação $(E(\pi))$ for menor do que a meta de inflação $\left(\pi^{t}\right)$, aqui definida como a mediana das expectativas do survey do Banco Central. Se a expectativa estiver entre a meta e um valor máximo de $20 \%$, então o índice é decrescente na expectativa de inflação, ou seja, quanto maior a expectativa de inflação, menor o índice. No entanto, quando a expectativa de inflação chega a $20 \%$, a credibilidade fica limitada a zero. Veja, então, que os valores extremos do índice são apenas para normalizar o resultado.

Com base neste índice, vários outros foram propostos tentando incorporar as especificidades do regime de metas de inflação brasileiro. Sicsú (2002) propõe um índice que leve em consideração a existência do centro da meta e da meta máxima:

$$
I C^{S}=100-\left\{\frac{\left|E(\pi)-\pi^{t}\right|}{\pi_{\max }^{t}-\pi_{t}} 100\right\}
$$

Veja que este índice é extremamente semelhante ao proposto por Cecchetti e Krause (2002), mas há duas diferenças marcantes. Em primeiro lugar, o índice não é normalizado, podendo atingir valores negativos e valores maiores do que 100. Além disso, Sicsú (2002) sugere, com este índice, que a meta máxima é um limite de credibilidade; veja que a meta máxima desempenha o papel da taxa de inflação de $20 \%$ em Cecchetti e Krause (2002).

Mendonça (2004) sugere um índice que é a normalização do índice de Sicsú (2002):

$$
I C^{M}=\left\{\begin{array}{c}
1, \text { se } E(\pi)=\pi^{t} \\
1-\frac{1}{\pi_{\max }^{t}-\pi^{t}}\left[E(\pi)-\pi^{t}\right], \text { se } \pi_{\min }^{t}<E(\pi)<\pi_{\max }^{t} \\
0, \text { se } E(\pi) \geq \pi_{\max }^{t} \text { ou } E(\pi) \leq \pi_{\min }^{t}
\end{array}\right.
$$

Note, no entanto, que a utilização dos limites propostos é bastante peculiar. Se a inflação for igual à meta, então há credibilidade total, mas se esta se desviar para cima, ou para baixo, há perda de credibilidade. O mais surpreendente não reside apenas no fato de a expectativa de inflação baixa indicar falta de credibilidade. Considere, por exemplo, que $E(\pi)$ esteja na vizinhança de $\pi_{\min }^{t}$. Se $E(\pi)$ se aproxima pela esquerda, então a credibilidade é zero. No entanto, se $E(\pi)$ se aproximar de $\pi_{\text {min }}^{t}$ pela direita, o índice é maior do que um. Note, então, que o índice apresenta uma descontinuidade na região do limite inferior da banda da meta de inflação.

É interessante ressaltar, neste ponto, que os resultados encontrados são semelhantes àqueles observados para Cecchetti e Krause (2002).

Nahon e Meurer (2005) sugerem uma nova variante dos índices anteriores, em que a credibilidade é máxima quando a expectativa estiver abaixo da limite superior da meta do Banco Central:

$$
I C^{N M_{a}}=\left\{\begin{array}{c}
1, \text { se } E(\pi) \leq \pi_{\max }^{t} \\
1-\frac{1}{\pi_{\max }^{t}-\pi^{t}}\left[E(\pi)-\pi_{\max }^{t}\right], \text { se } \pi_{\max }^{t}<E(\pi)<20 \% \\
0, \text { se } E(\pi) \geq 20 \%
\end{array}\right.
$$

Neste mesmo artigo, Nahon e Meurer (2005) ainda sugerem um índice mais simples que avalia se as expectativas estão próximas ou não da meta, em particular, da meta máxima:

$$
I C^{N M_{b}}=\frac{\pi_{\max }^{t}}{E(\pi)}
$$


Este índice tem como seu apelo principal a simplicidade. No entanto, ele não é normalizado, de modo que vai de $\infty$, quando a expectativa é próxima de zero, passando por um, quando a expectativa é igual à meta máxima, até zero, quando a expectativa é altíssima.

Para construir a meta do ano, adotamos um rigor normalmente ignorado que se refere a qual era a meta àquela data. Tome, como exemplo, o ano de 2003. Até 21 de janeiro, a meta era $4 \%$, quando, na Carta Aberta, o Banco Central divulgou que passaria a perseguir a meta de 8,5\%. Desse modo, os índices normalmente indicariam uma credibilidade mais alta, pois a distância da expectativa àquela data (11\%) para a meta final era menor do que a diferença para a meta que vigia no momento.

Apresentamos na Figura 8 um gráfico com a inflação prevista e a meta.

Figure 8: Expectativa e meta de inflação

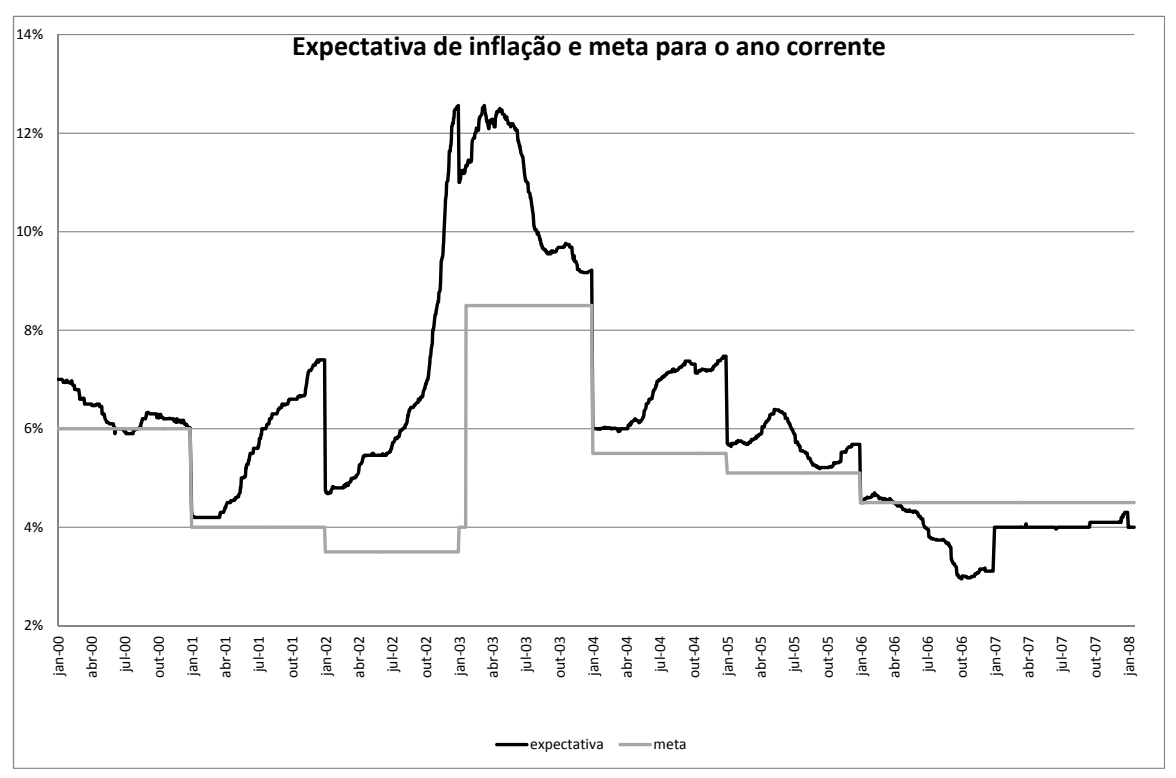

A Figura 8 mostra a meta de inflação, assim como a respectiva expectativa para o ano corrente. A partir destas duas séries, a maior parte dos índices constrói um índice de credibilidade. A crítica que pode ser feita a este método é que não leva em consideração a fonte de aumento das expectativas; se foi má condução da política econômica ou a ocorrência de um choque adverso.

Na Figura 9, construímos todos os índices para o caso brasileiro mais recente. O mais interessante de se observar nestes índices é que a credibilidade, em 2003, logo após a crise eleitoral, ficou bastante comprometida. Conforme se observa, o índice se reduziu bastante, mas o Banco Central conseguiu recuperar a credibilidade posteriormente. A trajetória mais recente sugere que a credibilidade tem se mantido alta e constante, dado que as expectativas estão estáveis, assim como a meta.

\section{2. Índice de Credibilidade com dispersão das expectativas}

Conforme apresentamos anteriormente, a matriz de probabilidades de transição teórica para um banco central com credibilidade total é composta por probabilidades de mudança de estado de 33,33\% para todos os estados. Isto advém do fato de que o ranking seria aleatório, de tal modo que a probabilidade de ser considerado otimista, pessimista ou mediano é a mesma independente do estado anterior em que o agente se encontrava. 
Figure 9: Índices de credibilidade no Brasil

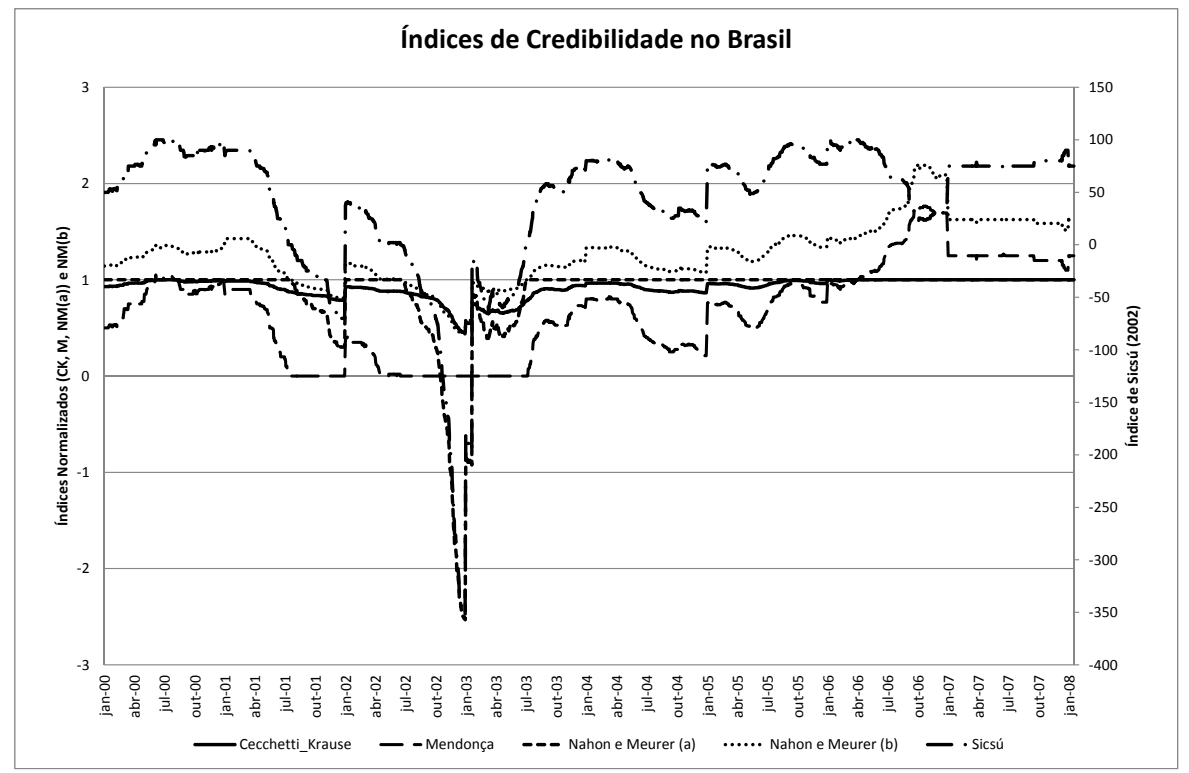

Desse modo, qualquer probabilidade que difira de 33,33\% deve ser vista como evidência de falta de credibilidade. Portanto, nossa medida de credibilidade é definida como a soma das diferenças absolutas entre a matriz de transição encontrada empiricamente e a matriz teórica de credibilidade total.

$O$ índice pode ser escrito como:

$$
\begin{aligned}
I C_{t} & =-\sum_{j=1}^{3}\left|\sum_{i=1}^{3}\right| p_{i j t}-\bar{p}_{i j t}|| \\
\bar{p}_{i j t} & =33,33
\end{aligned}
$$

$p_{i j t}$ : probabilidade de mudança do estado $i$ para o estado $j$ no instante $t$.

Da forma como o índice está construído, quanto menor seu valor, menor a credibilidade, pois maior a diferença para as probabilidades teóricas que ocorrem sob credibilidade perfeita. $O$ resultado pode ser visto na Figura 10: ${ }^{10}$

Conforme se observa, até 2004, o índice se assemelha ao que costumamos observar nos índices convencionais calculados para o Brasil, tal como visto anteriormente. Para facilitar, apresentamos uma figura com os índices anteriores e os índices propostos em um mesmo gráfico.

As quedas de 2003 e 2004 são semelhantes, mas há divergências entre o que encontramos neste índice com o que a literatura sugere. Em primeiro lugar, uma vez que as expectativas têm ficado abaixo da meta de inflação, os índices de credibilidade consideram a credibilidade constante e alta. Veja, no entanto, que isto não é suficiente para determinarmos a credibilidade de um banco central. Ainda que as expectativas sejam baixas, a credibilidade pode variar, o que sem dúvida é uma contribuição do índice proposto. Além disso, a recente queda da credibilidade do Banco Central utilizando um índice de Markov, em contraposição à manutenção da credibilidade evidenciada nos demais índices,

\footnotetext{
${ }^{10}$ Normalizamos o índice de credibilidade para ser mais facilmente entendido da seguinte maneira: $I C_{t}^{N}=\frac{I C_{t}-I C_{\min }}{I C_{\max }-I C_{\min }}$.
} 
Figure 10: Índice de credibilidade com base na expectativa de doze meses à frente

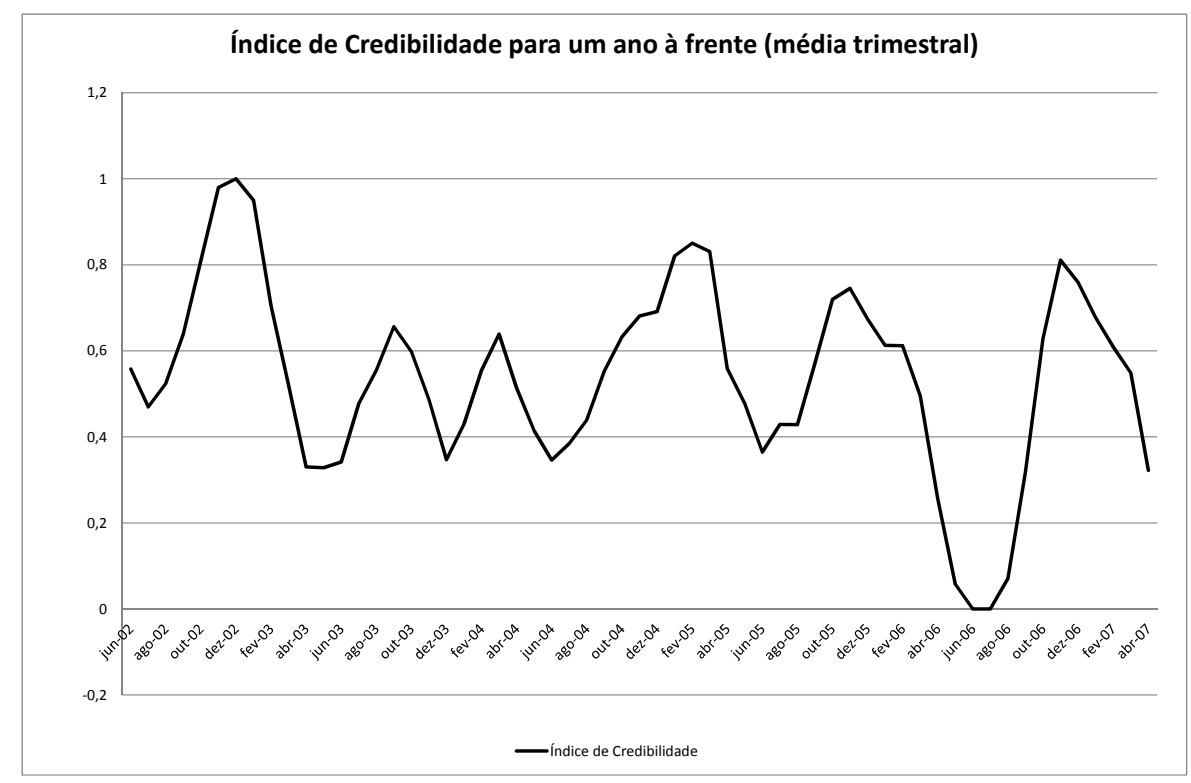

Figure 11: Comparação dos índices de credibilidade

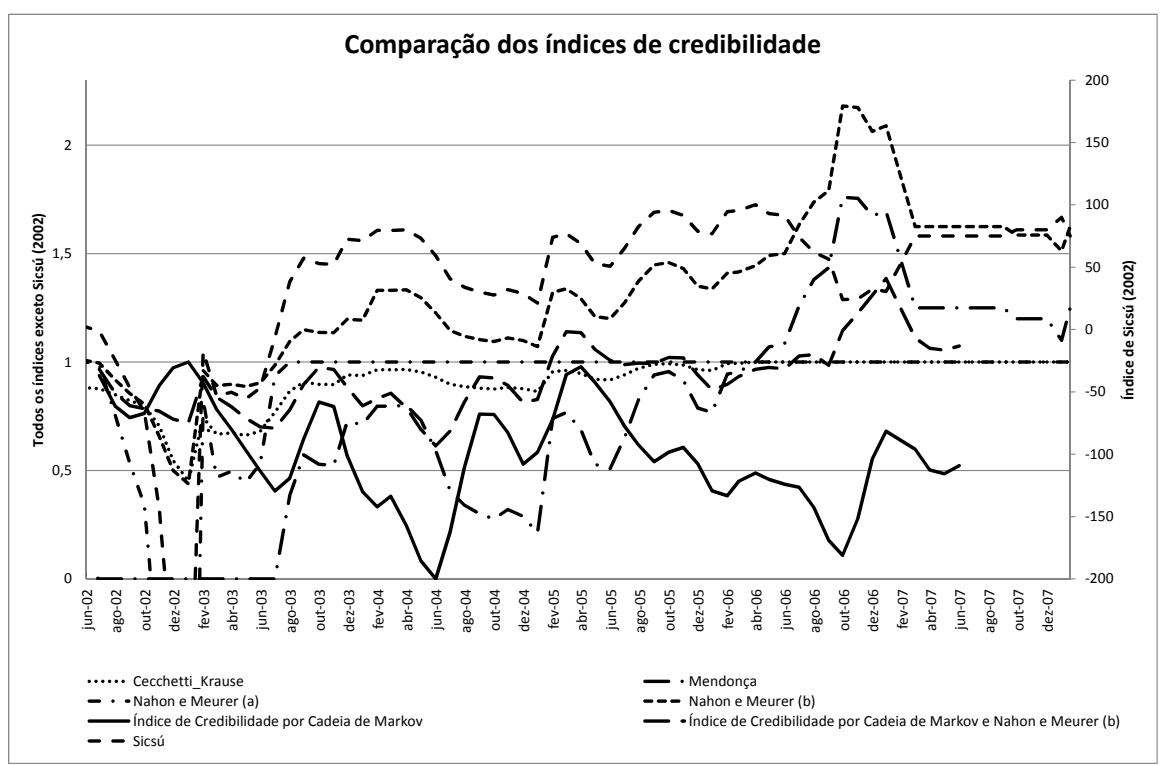


também deve ser ressaltada. Mais uma vez, como dito anteriormente, tal índice é complementar aos demais. Há muitas possibilidades de construção de índices que captem tanto a heterogeneidade quanto o nível das expectativas; apresentamos apenas um, composto $50 \%$ pelo índice de matrizes de transição e $50 \%$ por Nahon e Meurer (b). Como esperado, combina elementos dos dois tipos de índices discutidos anteriormente.

\section{CONCLUSÃO}

Neste artigo, propusemos uma nova forma de análise das expectativas de inflação utilizando uma base de dados de expectativa de inflação desagregada por agente.

Com diferentes horizontes temporais, sugerimos que uma maneira de avaliar a credibilidade do Banco Central é identificando se um agente se mantém otimista ou pessimista ao longo do tempo. Se os agentes mudarem os seus comportamentos aleatoriamente, isto indicará que há credibilidade. No entanto, se houver persistência nos estados, há desconfiança da verdadeira aversão do banco central à inflação, fazendo com que alguns agentes mantenham-se otimistas e outros, pessimistas. A hipótese subjacente é que a fonte de heterogeneidade advém de desconfiança com relação à verdadeira aversão do Banco Central à inflação.

Os resultados encontrados sugerem que agentes otimistas e pessimistas se comportam de forma semelhante, isto é, as trajetórias temporais dos otimistas e dos pessimistas é semelhante.

Diante deste resultado, construímos um novo índice de credibilidade que avalia o papel de cada agente no ranking mensal de expectativas, independente do valor em si da expectativa frente à meta. Os resultados são bem interessantes, sugerindo uma queda na credibilidade em 2003 e 2004, quando o Banco Central teve que alterar suas metas.

Este novo índice apresentado é uma proposta adicional para medir a credibilidade que tem, como principal atrativo, a utilização da dispersão das expectativas. No entanto, deve ser ressaltado que este índice é complementar aos demais já existentes na literatura, que dão maior ênfase à meta de inflação explicitamente. Em nosso índice, que pode ser visto, de certo modo, como o outro extremo em relação aos índices já propostos, não há qualquer menção ao nível das expectativas, apenas à persistência das expectativas dos agentes. No entanto, tal como sugerido, é possível montar índices que combinem medidas de heterogeneidade e de nível, de modo a levar em conta mais fatores que afetam a credibilidade do Banco Central.

\section{BIBLIOGRAFIA}

Blanchard, O. (1984). The Lucas critique and the Volcker deflation. The American Economic Review, 74:211-215.

Blinder, A. S. (1999). Central Bank credibility: Why do we care? How do we build it? Working Paper Series 7161, National Bureau of Economic Research.

Cecchetti, S. \& Krause, S. (2002). Central Bank structure, policy efficiency and macroeconomic performance: Exploring empirical relationships. Federal Reserve Bank of St. Louis Economic Review, 84:47-59.

Gantmacher, F. (2005). Applications of the Theory of Matrices. Dover Publications.

Garcia, M. \& Lowenkron, A. (2007). Monetary policy credibility and inflation risk premium: A model with application to Brazilian data. Texto para Discussão 543, Departamento de Economia - PUC-Rio.

Hardouvelis, A. \& Barnhart, W. (1989). The evolution of federal reserve credibility: 1978-1984. The Review of Economics and Statistics, 71:385-393. 
Kydland, F. \& Prescott, E. (1977). Rules rather than discretion: The inconsistency of optimal plans. The Journal of Political Economy, 85:473-492.

Marques, A., Fachada, P., \& Cavalcanti, D. (2003). Sistema banco central de expectativas de mercado. Notas Técnicas 36, Banco Central do Brasil.

Mendonça, H. F. (2004). Mensurando a credibilidade do regime de metas inflacionárias no Brasil. Revista de Economia Política, 24:344-350.

Mendonça, H. F. \& Souza, G. (2007). Credibilidade do regime de metas para inflação no Brasil. Pesquisa e Planejamento Econômico, 37:247-282.

Nahon, B. \& Meurer, R. (2005). A relação entre a credibilidade do banco central e a inflação no Brasil do regime de metas inflacionárias. In ANPEC-Sul, editor, Encontro de Economia da Região Sul 8, Porto Alegre. Anais eletrônicos. Disponível em: http://www.ppge.ufrgs.br/anpecsul2005/ artigos/area2-01.pdf.

Razzak, W. (2001). Are inflation-targeting regimes credible? Econometric evidence. Working paper, Reserve Bank of New Zealand.

Sargent, T. (1982). The ends of four big inflations. In Hall, R., editor, Inflation: Causes and Effects. University of Chicago Press, Chicago.

Sicsú, J. (2002). Expectativas inflacionárias no regime de metas de inflação: Uma análise preliminar do caso brasileiro. Economia Aplicada, 6:703-711.

Svensson, L. (1993). The simplest test of inflation target credibility. NBER Working Paper Series 4604, National Bureau of Economic Research. 


\section{A. APÊNDICE}

Este Apêndice é composto de três seções. Na primeira seção, resumimos o arcabouço matemático de Cadeias de Markov utilizado. Na segunda, propomos uma simulação teórica que mostre a relação entre a dispersão de expectativas e a incerteza quanto ao coeficiente de aversão à inflação do Banco Central. Na terceira seção, destacamos os resultados encontrados para expectativas com horizontes mais longos: dois, três e quatro anos à frente.

\section{A.1. 0 arcabouço matemático ${ }^{11}$}

Seja um sistema com $n$ possíveis estados: $S_{1}, S_{2}, \ldots, S_{n}$ e instantes no tempo: $t_{0}, t_{1}, \ldots$

Suponha que, em cada instante, o sistema só possa permanecer em um estado.

Defina $p_{i j}$ como a probabilidade de que o sistema esteja no estado $S_{j}$ no instante $t_{k}$, supondo que o sistema estava no estado $S_{i}$ no instante $t_{k-1}$. Dessa maneira, é imediato vermos que $p_{i j}$ não é variante no tempo.

Definição: $P=\left(p_{i j}\right)_{1}^{n}$ é uma cadeia de Markov com número finito de estados tal que:

- $p_{i j} \geq 0$;

- $\sum_{j=1}^{n} p_{i j}=1(i, j=1,2, \cdots, n)$

Definição: Uma matriz quadrada $P=\left(p_{i j}\right)_{1}^{n}$ é dita estocástica se a matriz $P$ é não negativa e se toda soma dos elementos da linha é igual a 1 .

Dessa maneira, uma matriz de probabilidades de transição de uma cadeia de Markov homogênea é estocástica e, por outro lado, uma matriz estocástica arbitrária pode ser vista como uma matriz de probabilidades de uma Cadeia de Markov homogênea.

Estes fatos podem ser reescritos dizendo que uma matriz $P$ não-negativa é estocástica se, e somente se, o vetor $(1,1, \ldots, 1)$ é o autovetor característico de $P$, cujo autovalor é 1 .

Veja que as regras para somar e multiplicar probabilidades são triviais:

$$
p_{i j}^{(q+1)}=\sum_{h=1}^{n}\left(p_{i h}^{(q)}\right) p_{h j}
$$

Esta expressão está apenas dizendo que devemos somar todas as probabilidades intermediárias para encontrarmos uma probabilidade final.

\footnotetext{
${ }^{11}$ Uma boa referência para Cadeia de Markov é Gantmacher (2005).
} 


\section{A.2. Simulação teórica}

Como forma de melhor explicitar o índice de credibilidade sugerido, apresentamos uma simulação teórica. Conforme dito anteriormente, a credibilidade, no nosso caso, surge da desconfiança sobre a verdadeira aversão do Banco Central à inflação. Desse modo, apresentamos uma breve simulação. Suponha que existam três agentes na economia: otimista, mediano e pessimista. Cada um deles acredita em um certo coeficiente da aversão à inflação do Banco Central, tal que, para cada agente $j$ :

Construção da expectativa de inflação do agente $j\left(\pi_{t}^{j}\right)$ :

$$
\pi_{t}^{j}=\gamma x_{t-1}^{j}+\vartheta_{t}^{j}
$$

Esta é a equação de Phillips em expectativas, ou seja, como as expectativas de inflação e de hiato se comportam. Além disso, adicionamos um erro aleatório por estarmos utilizando as expectativas.

Construção da expectativa de hiato do agente $j\left(x_{t}^{j}\right)$ :

$$
x_{t}^{j}=-\sigma\left(R_{t}^{j}-\pi_{t}^{j}-r_{t}\right)
$$

Para o lado da demanda, utilizamos uma versão da curva IS que relaciona a expectativa do hiato do produto com a expectativa da taxa de juros real, sendo $R_{t}^{j}$ a taxa nominal de juros que o agente $j$ acha que vai vigorar e $r_{t}$ a taxa natural de juros que não afeta o hiato do produto.

Taylor:

$$
R_{t}^{j}=\phi_{r} R_{t-1}+\phi_{\pi}^{j} \pi_{t-1}+\phi_{x} x_{t-1}
$$

Por fim, para fechar o modelo, utilizamos a Curva de Taylor que determina como o Banco Central reage a choques inflacionários e no produto. Conforme se pode notar, o único parâmetro dependente do agente é $\phi_{\pi}^{j}$, que determina a resposta dos juros à inflação.

Este modelo é o mais simples em que podemos ter três agentes construindo expectativas para inflação, hiato e taxa de juros. Mais ainda, os agentes utilizam as próprias expectativas quando estão no período contemporâneo, pois não conhecem os verdadeiros valores, mas utilizam as verdadeiras variáveis defasadas, exceto o hiato devido à incerteza quanto à sua mensuração. Há, ainda, um choque normal idiossincrático ao agente na definição da inflação em nossa Phillips estilizada, definido como um choque normal de média zero e variância 0,1 .

Além disso, precisamos agregar as expectativas gerais para construir o modelo mais geral.

Expectativas:

$$
E_{t}\left(\pi_{t+1}\right)=\chi E_{t}\left(\pi_{t+1}^{\text {otimista }}\right)+\varphi E_{t}\left(\pi_{t+1}^{\text {pessimista }}\right)+(1-\chi-\varphi) E_{t}\left(\pi_{t+1}^{\text {mediano }}\right)
$$

Se supusermos esta linearidade, não haveria razão para que os diferentes agentes, mais dispersos ou não, afetassem a inflação. De todo modo, o desvio padrão das expectativas seria maior quanto maior fosse a disparidade entre os verdadeiros coeficientes.

O verdadeiro modelo que rege a economia é dado por uma curva de Phillips que contém a expectativa de inflação e o hiato do produto, além das curvas IS e Taylor.

$$
\begin{aligned}
\pi_{t} & =\beta E_{t}\left(\pi_{t+1}\right)+\gamma x_{t}+\varepsilon_{t} \\
x_{t} & =-\sigma\left(R_{t}-E_{t} \pi_{t+1}-r_{t}\right)+v_{t} \\
R_{t} & =\phi_{r} R_{t-1}+\phi_{\pi} \pi_{t-1}+\phi_{x} x_{t-1}+\eta_{t}
\end{aligned}
$$

Utilizamos, para facilitar, uma economia fechada, mas isto não significa perda de generalidade do exemplo. Além disso, os choques utilizados são normalmente distribuídos e independentes entre si. Por 
fim, cabe mencionar que as expectativas de inflação são formadas a partir da média das expectativas dos agentes.

A credibilidade está, desse modo, na crença com relação ao coeficiente de resposta da taxa de juros à inflação, apresentada na Regra de Taylor, que depende de $j$, índice que define o agente mediano, pessimista ou otimista.

O exercício utilizado nesta seção consiste em definir três agentes com diferentes crenças com relação ao verdadeiro valor do coeficiente da Regra de Taylor. A partir de então, rodamos o sistema sujeito a choques normalmente distribuídos e dependendo apenas da condição inicial.

Apresentaremos dois exemplos em que o coeficiente do agente mediano é igual ao coeficiente verdadeiro; o agente otimista acredita em um coeficiente maior (aversão maior) e o agente pessimista acredita em um coeficiente menor (aversão menor). A distinção entre os dois exemplos consiste na amplitude entre as diferenças do coeficiente de aversão que o pessimista e o otimista têm. No exemplo que definiremos "com credibilidade", os coeficientes são próximos do verdadeiro, ao passo que no exercício "sem credibilidade", o pessimista acredita em um coeficiente menor e o otimista em um coeficiente maior do que aquele observado "com credibilidade". O agente mediano possui coeficientes iguais ao verdadeiro do Banco Central em ambos os casos. ${ }^{12}$

Quando não há viés sistemático, se a média dos coeficientes for igual, ainda que a dispersão dos coeficientes seja maior em um caso do que em outro, nenhuma das variáveis macroeconômicas indicará isto, pois o nível não se altera. No entanto, a dispersão das expectativas será maior quanto maior for a dispersão nos coeficientes, conforme pode ser visto no gráfico da Figura 12.

Figure A-1: Dispersão das expectativas de inflação

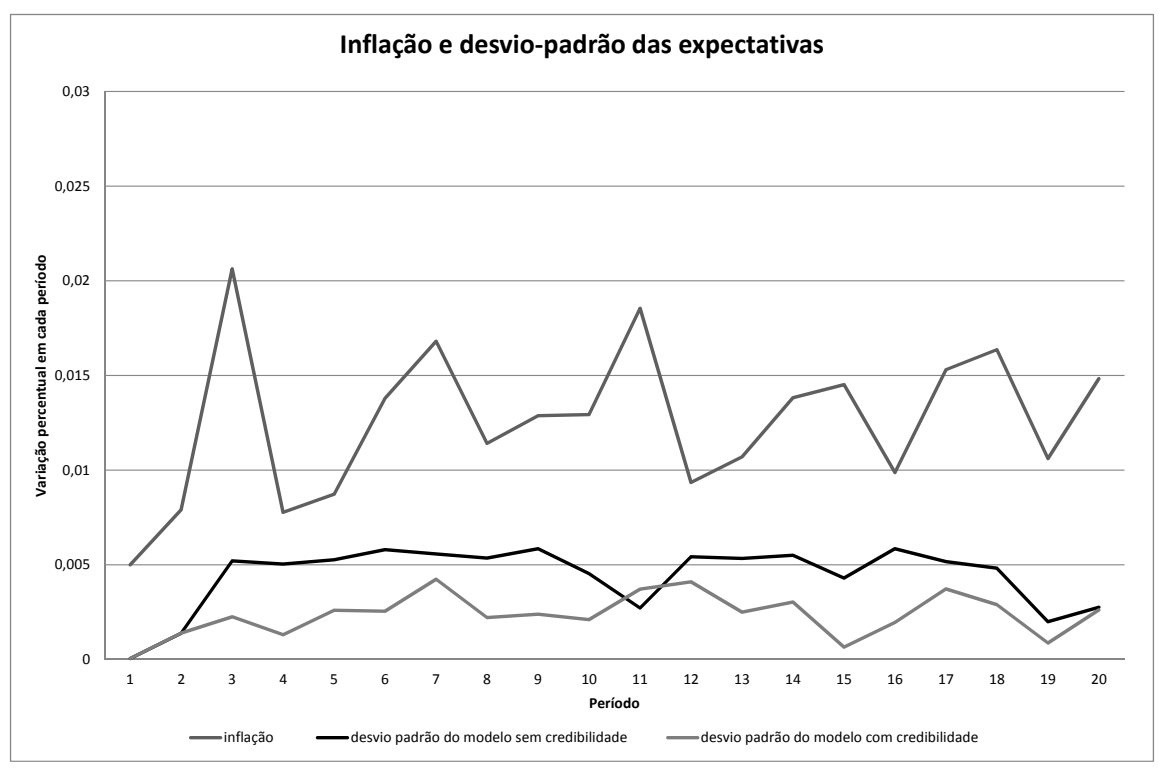

A Figura 12 sugere que, quanto maior for a dispersão do coeficiente, maior será a dispersão das expectativas. Este resultado é bastante intuitivo e sugere que a ancoragem das expectativas passa por uma maior confiabilidade do verdadeiro coeficiente de inflação da Regra de Taylor do Banco Central. No entanto, deve ser ressaltado que, se não houver alteração das expectativas, isto não afeta o nível da inflação.

\footnotetext{
${ }^{12}$ A parametrização completa pode ser obtida com o autor.
} 
Para deixar mais clara a motivação para o índice de credibilidade sugerido, apresentamos um gráfico na Figura 13 com o número de mudanças de estado por período.

Figure A-2: Número de mudanças de estado por período

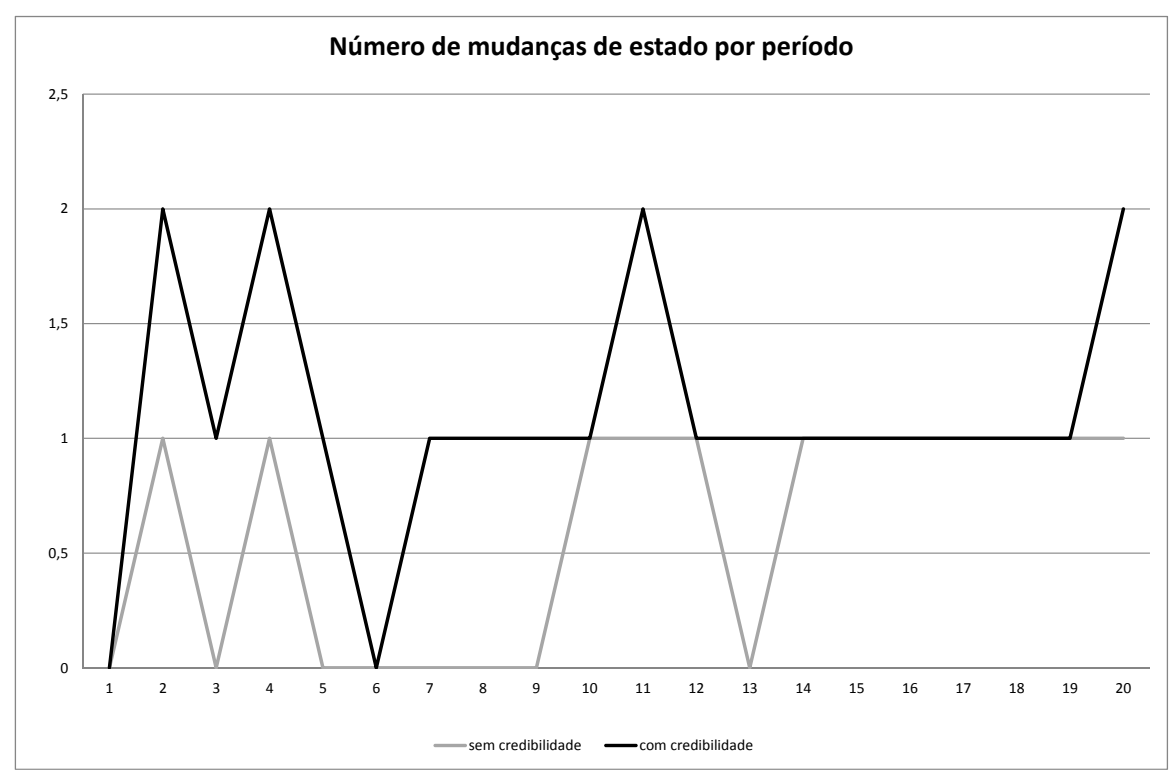

A Figura 13 ilustra o número de mudanças de estado do agente por período. Isto significa que, por exemplo, um agente otimista, cujo coeficiente de aversão à inflação na Taylor seria maior, tenderia a ter a expectativa de inflação mais baixa. No entanto, quando ele passa a ter expectativas maiores do que o agente mediano, há uma mudança na ordem; desse modo o número de mudanças no período assume o valor um. Assim, quanto maior o número de mudanças, mais instável é a ordem das expectativas de inflação dos agentes pessimistas, medianos e otimistas. Conforme pode ser observado, quando há uma convergência do coeficiente de aversão ao risco, maior a ocorrência de mudanças, tal como sugerido em nosso índice de credibilidade. 


\section{A.3. Resultados utilizando expectativas de horizontes longos}

Nesta seção, ilustramos os resultados para horizontes mais longos de expectativas: dois anos, três anos e quatro anos à frente. Os resultados são bastante sensíveis, pois há um número reduzido de agentes reportando suas expectativas. De modo geral, a conclusão que emerge ao analisarmos estes resultados é que as probabilidades de permanência no mesmo estado, quais sejam otimistas, pessimistas ou medianos, aumentam quanto maior for o horizonte sobre o qual são feitas as expectativas.

Figure A-3: Comportamento das expectativas para dois anos à frente

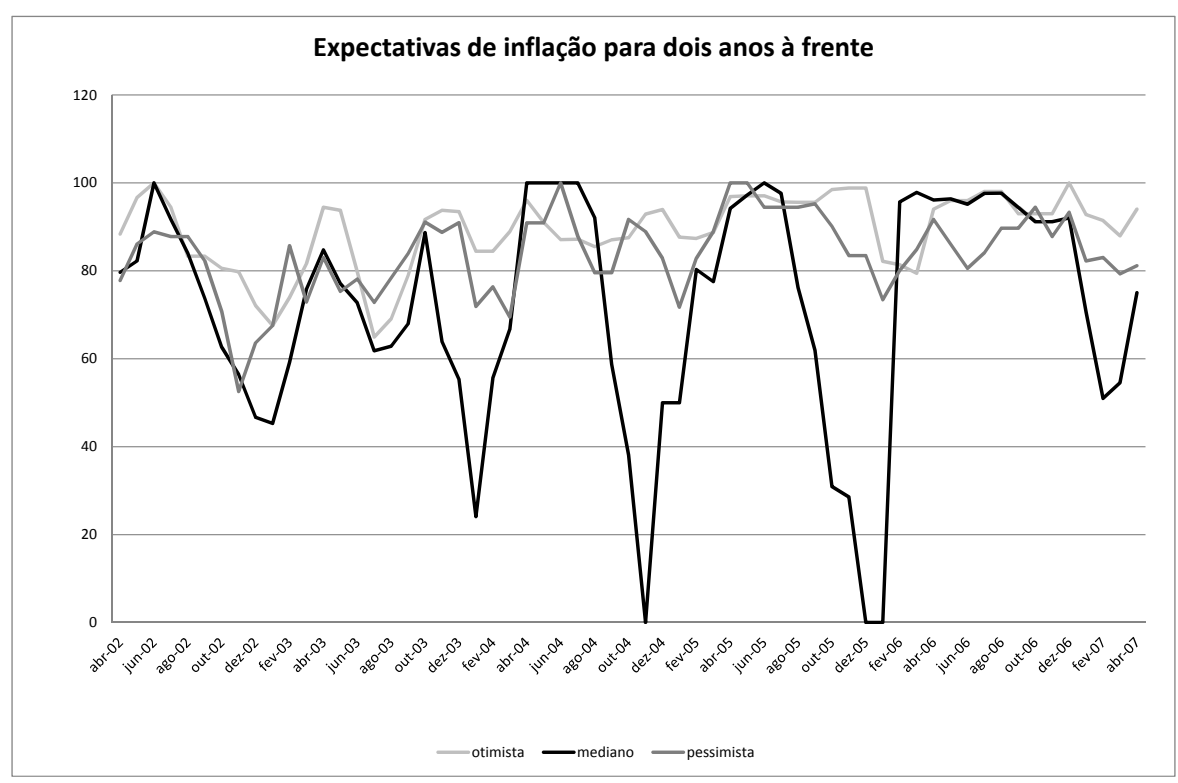


Figure A-4: Comportamento das expectativas para três anos à frente

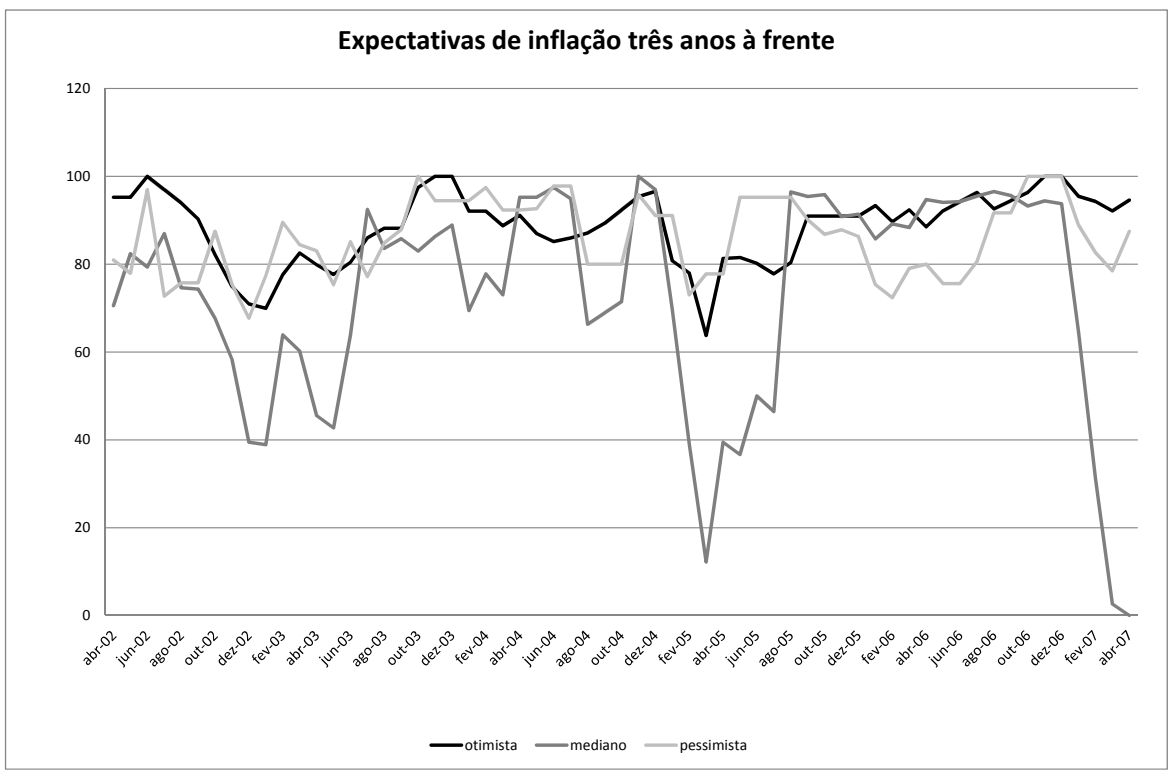

Figure A-5: Comportamento das expectativas para quatro anos à frente

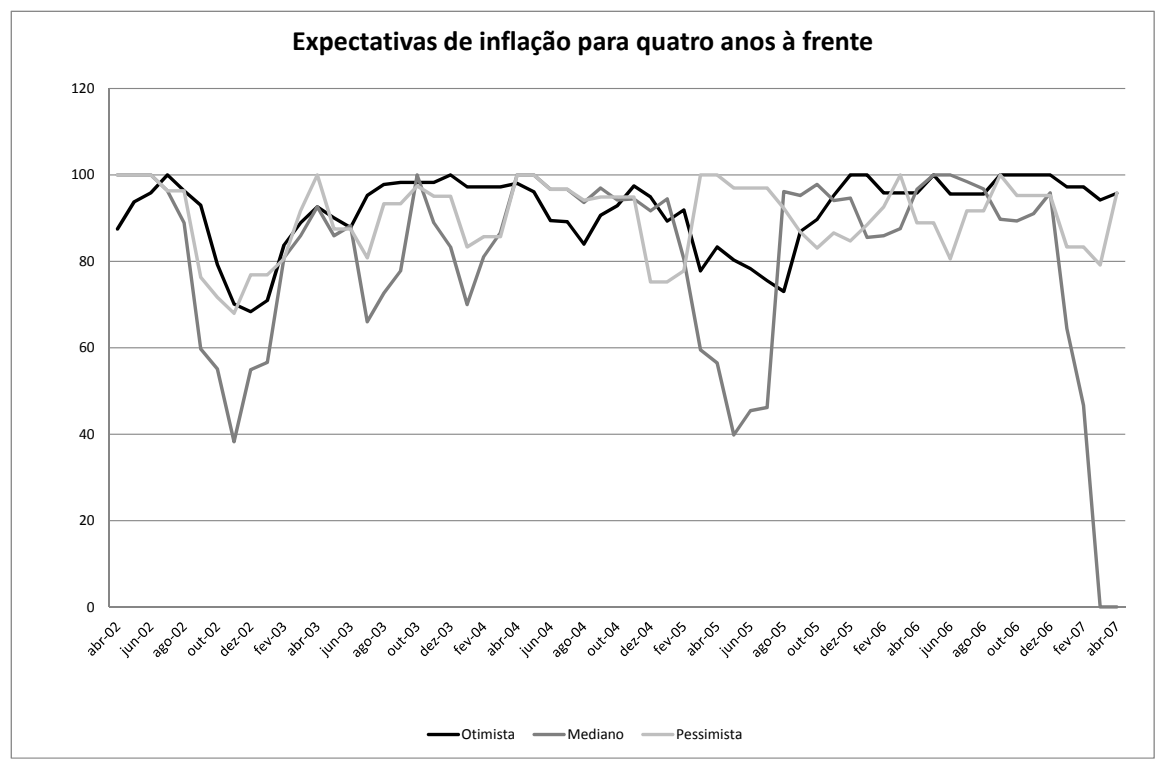

